\title{
Virtudes epistêmicas na prática do historiador: o caso da sensibilidade histórica na historiografia brasileira (1980-1990)
}

\author{
Epistemic virtues and the historian's practices: the case of historical \\ sensibility on Brazilian historiography (1980-1990)
}

\author{
João Rodolfo Munhoz Ohara \\ oharajrm@gmail.com \\ Doutorando em História (Bolsista Fapesp) \\ Universidade Estadual Paulista/Assis \\ Rua Primo Paganini, 941 \\ 18608-190 - Botucatu - São Paulo \\ Brasil
}

\begin{abstract}
Resumo
O que significa "sensibilidade histórica", e como tal característica foi considerada virtuosa para o ofício do historiador? Este artigo busca investigar tal questão tendo em vista a historiografia universitária brasileira entre 1980 e 1990, a partir da leitura de resenhas, obituários e artigos de homenagem publicados em periódicos acadêmicos da área de história no período. O tema da sensibilidade histórica aparece em dois sentidos diferentes: enquanto virtude epistêmica e enquanto meta-virtude, orientando o exercício de outras virtudes. Não se trata, porém, de simples ambiguidade ou contradição; diferentes concepções de história implicam diferentes maneiras de ser historiador, e, portanto, mobilizam diferentes repertórios de características virtuosas.
\end{abstract}

\section{Palavras-chave}

Virtudes epistêmicas; Historiografia brasileira; Discurso.

\section{Abstract}

What could it mean to say that one has "historical sensibility"? This paper investigates this question and how such sensibility was placed among the desirable values for a historian to hold and to exercise in his own professional practices. The main sources for this study are book reviews, obituaries, and homage articles published in Brazilian, history journals between 1980 and 1990. Historical sensibility, then, seems to appear in two different senses: (1) as an epistemic virtue and (2) as a meta-virtue, orienting the exercise of other virtues. This does not mean that historians properly disagreed about the meaning of historical sensibility, but rather that these two different uses refer to distinct repertoires of virtues configured around different notions of what is proper history - and, therefore, of what is a proper historian.

\section{Keywords}

Epistemic virtues; Brazilian historiography; Discourse. 
Quando afirma que o estudo histórico é "como o veículo saído de uma fábrica", e que está "mais ligado ao complexo de uma fabricação específica e coletiva do que ao estatuto de efeito de uma filosofia pessoal" (CERTEAU 2008, p. 73), Michel de Certeau dá uma direção para pensarmos a relação complexa entre o historiador enquanto indivíduo e o lugar social que condiciona sua prática. Isso porque o lugar (ou, em outro vocabulário conceitual, o campo $)^{1}$ impõe determinadas regras e procedimentos para validar não apenas o que conta como texto de história, mas também quem pode falar como historiador. Assim, é em relação a repertórios limitados e históricos de valores que um historiador, efetivamente, aprende a ser historiador: do modelo filológico clássico ao historiador politicamente engajado, diferentes concepções de história prescrevem diferentes maneiras de ser, diferentes ethos de historiador.

Deslocar a atenção da crítica teórica das narrativas históricas para as práticas que as estruturam requer, no entanto, a ampliação do nosso aparato conceitual. É neste sentido que os conceitos de virtude epistêmica e persona acadêmica, propostos por Herman Paul (2011; 2012b; 2013; 2014), nos ajudam a estudar as práticas historiográficas. Inspirando-se, por um lado, na discussão da virtue epistemology anglo-saxã, e, de outro, nos estudos de Lorraine Daston e Peter Galison (2007), Paul propõe que o conceito de virtude epistêmica serve de ferramenta útil para o historiador da historiografia ou o teórico da história que se preocupe em questionar a produção historiográfica enquanto prática, mais do que seus produtos finais acabados. ${ }^{2}$ Ademais, Daston e Otto Sibum (2003), bem como Conal Condren, Stephen Gaukroger e Ian Hunter (2006), também servem de referência para o conceito de persona acadêmica, que articula um segundo nível de trabalho, no qual virtudes (epistêmicas, morais, políticas) se articulam para formar determinados modelos de conduta, em relação aos quais os indivíduos aprendem a ser historiadores.

Neste artigo, defino os conceitos de virtude epistêmica e, mais brevemente, persona acadêmica, para, a seguir, dedicar-me à análise de um tema que aparece em certos textos - resenhas, obituários e artigos de homenagem - publicados em periódicos acadêmicos da área de história, no Brasil, entre 1980 e 1990: a "sensibilidade histórica". A partir da leitura atenta dos materiais, evidencio que o termo se refere a dois enunciados que organizam as práticas dos historiadores brasileiros do período: de um lado, a sensibilidade histórica constitui uma virtude epistêmica em si, enquanto capacidade de situar elementos individuais em uma cadeia mais ampla (o "processo histórico"); de outro, sensibilidade histórica se refere a uma meta-virtude, cujo papel é dar sentido ao exercício de

\footnotetext{
${ }_{1}^{1}$ Pode-se argumentar que a delimitação do lugar social operada por Certeau e o conceito de campo em Pierre Bourdieu não são intercambiáveis - o que está correto. Entretanto, para o propósito deste artigo, interpretase tanto o lugar quanto o campo em relação ao conjunto de regras que estrutura e legitima as práticas e os produtos da atividade historiográfica. Ademais, o próprio Certeau fala da investigação do lugar como uma "sociologia da historiografia" (CERTEAU 2008, p. 78).

2 Com fins de precisão conceitual, noto que o artigo de 2011 de Paul fala em termos de "performatividade" e "performance", e não de práticas. Em seus textos subsequentes, no entanto, o termo quase desaparece. Para minha perspectiva, opto por aproximar a proposta do conceito de prática no sentido de formular uma arquitetura conceitual mais ou menos coesa com relação às análises mais fundamentais de Michel de Certeau. Agradeço à prof. Maria da Glória de Oliveira por me apontar essa questão.
} 
outras virtudes epistêmicas, como a erudição, o pensamento crítico e a leitura atenta. Essa dispersão não é acidental; ela demonstra, em certa medida, que os repertórios de virtudes epistêmicas em um dado contexto estão intimamente ligados a diferentes concepções de história. Em outras palavras, diferentes concepções de história implicam diferentes maneiras de ser historiador. Assim, este breve exercício de análise histórica visa evidenciar, a partir de um caso específico, o funcionamento de determinados elementos que atuam na produção da subjetividade do historiador enquanto historiador.

\section{Virtude epistêmica}

A "epistemologia das virtudes" é um setor da epistemologia anglo-saxã que, desde os textos seminais de Ernest Sosa (1980) e Linda Zagzebski (1996), propôs a análise de problemas epistemológicos a partir do conceito de virtude epistêmica. A própria definição do conceito possui duas variantes: para confiabilistas, como Sosa, virtude epistêmica é faculdade cognitiva confiável, tal que seu exercício seja condutivo à verdade; para responsabilistas, como Zagzebski, virtude epistêmica é traço de caráter ou disposição que um agente epistemicamente responsável possuiria ou demonstraria ao produzir conhecimento. ${ }^{3}$ Apesar dessa distinção, alguns temas comuns às abordagens confiabilista e responsabilista podem ser elencados: (1) o papel normativo da epistemologia, discutindo os problemas do ceticismo e da justificação do conhecimento, por exemplo; (2) a responsabilidade do agente na produção de conhecimento, argumentando que conhecimento é crença verdadeira produzida por virtude epistêmica, e não por sorte ou acidente; (3) o problema do valor do conhecimento (Cf.: GRECO 2010).

De outro lado, Lorraine Daston e Peter Galison definem virtudes epistêmicas como "normas que são internalizadas e aplicadas [enforced] por apelo a valores éticos, assim como eficácia pragmática em assegurar o conhecimento" (DASTON; GALISON 2007, p. 40-41). Em sua história da objetividade, narram as mutações sofridas por tal virtude epistêmica - de fidelidade-à-natureza [truth-to-nature], passando pela objetividade mecânica, até o julgamento treinado - e, com isso, visam demostrar as reconfigurações nas maneiras de fazer ciência e de ser cientista entre os séculos XVII e XX. Em contraste ao interesse filosóficoanalítico da epistemologia das virtudes, a história de Daston e Galison delimita a historicidade das virtudes epistêmicas e recoloca a produção do próprio sujeito de conhecimento no centro das preocupações: "O domínio de práticas científicas é inevitavelmente ligado ao domínio de si, o assíduo cultivo de um certo tipo de si mesmo [self]" (DASTON; GALISON 2007, p. 40).

Essas duas instâncias delimitam bem aquilo que gostaria de classificar como uso filosófico e uso histórico do conceito de virtude epistêmica. Enquanto

\footnotetext{
${ }^{3}$ Evidentemente, trata-se de caracterização sumária, com fins didáticos. Para mais detalhes introdutórios, ver Greco (2010) e Kvanvig (2011). Vale ressaltar que a epistemologia das virtudes, embora tenha emergido em proximidade com a ética das virtudes (virtueethics), constitui um campo à parte de reflexão na filosofia. Sobre a relação entre ética das virtudes e epistemologia das virtudes da perspectiva da teoria da história, ver Froyeman (2012) e a resposta de Paul (2012a).
} 
o filósofo coloca suas questões no nível mais alto de abstração, buscando as condições e características universais das virtudes epistêmicas, o historiador está mais interessado em como diferentes arranjos históricos puderam considerar diferentes características como virtuosas no exercício da produção de conhecimento. Não se trata de postular a superioridade de uma abordagem em relação à outra, mas de evidenciar que os protocolos de trabalho operam em níveis diferentes de análise. Ademais, tal distinção também não significa que historiadores não lancem mão de abstrações - seria absurdo pensar em uma narrativa histórica sem articulação teórica, mesmo que oculta, dissimulada ou "inconsciente"; a diferença está, parece-me, em que, enquanto o filósofo se pergunta "o que é virtude epistêmica?", o historiador rearticula a questão para "o que é virtude epistêmica para tal ou qual grupo?"

Ora, em seu artigo de 2011, Herman Paul propõe que o conceito de virtude epistêmica, naquilo que delimitei aqui como uso histórico, deve fornecer um vocabulário conceitual de grande valor às pesquisas nas áreas da teoria e da história da historiografia: "Sugiro que o conceito de 'virtudes epistêmicas' [...] nos permite conceber os 'fazeres' do historiador como performances idealmente reguladas por virtudes tais como diligência, precisão e veracidade" (PAUL 2011, p. 4). Trata-se de deslocar o foco das questões do texto histórico enquanto produto acabado para o que Paul chama de "performances":

Historiadores se curvando sobre documentos antigos cuidadosamente removidos de pastas cinzentas em caixas marrons de arquivo, ou escrevendo um rascunho de um artigo, estão engajados em atividades performativas. Eles leem, selecionam, associam, interpretam, definem e formulam, sem mencionar uma dúzia de outras atividades [...] (PAUL 2011, p. 3, grifo meu).

Parece-me interessante notar que aquilo que Paul delimita como performance se aproxima muito da dimensão prática da operação historiográfica tal qual analisada por Certeau. Assim, pode-se notar um impulso comum de deslocamento de interesse: para além das discussões sobre os atributos e o funcionamento da estrutura narrativa do texto histórico, pretende-se problematizar as práticas que Ihe dão forma, desde a separação e coleta dos documentos - "Em história, tudo começa com o gesto de separar, de reunir, de transformar em 'documentos' certos objetos distribuídos de outra maneira" (CERTEAU 2008, p. 81, grifo no original) - até a escrita enquanto prática - "De fato, a escrita histórica - ou historiadora permanece controlada pelas práticas das quais resulta; bem mais do que isto, ela própria é uma prática social que confere ao seu leitor um lugar bem determinado [...]" (CERTEAU 2008, p. 95, grifo meu). ${ }^{4}$ Mais do que a análise do funcionamento interno do texto histórico, o foco de análise aqui permanece sobre as operações que condicionam a produção do mesmo - as regras do campo, a produção de indivíduos aptos a falar do passado, o funcionamento coletivo da disciplina.

\footnotetext{
${ }^{4}$ Neste sentido, em minha leitura de Paul, substituo o termo performance pelo de prática não apenas com fins de consistência terminológica, mas também de consistência conceitual. Ademais, o próprio Paul, mais ao final do artigo, lança mão do conceito de práticas (PAUL 2011, p. 11).
} 
Paul nota que a linguagem moralizante em relação ao trabalho historiográfico - ou seja, a prescrição de determinadas condutas para que um historiador realize bem seu trabalho - já está presente quando autores célebres de manuais históricos falam de seu trabalho, como no caso de Langlois e Seignobos, ou mesmo de Marc Bloch (PAUL 2011, p. 5-7). Mais ainda, esses valores são instrumentais também nas instâncias em que um historiador é avaliado por seus pares, como no caso de resenhas, pareceres, prefácios, obituários ou homenagens (PAUL 2011, p. 7). Neste sentido, parece-me, ao pesquisador caberia mapear as virtudes e os vícios elencados pelos historiadores e analisar as configurações coletivas desses valores, as correlações que estabelecem entre $\mathrm{si}$, bem como as afinidades entre determinados valores ou repertórios de valores e determinadas concepções de história. ${ }^{5}$

Ora, apesar dessa mudança substantiva de foco, as fontes para tal estudo permanecem escritas - afinal, paratextos e textos auxiliares ainda são textos. Poderíamos questionar, portanto, a pertinência desse deslocamento, uma vez que não se tratam de observações etnológicas dos historiadores em prática, mas da leitura de textos. Por outro lado, a própria análise desses textos é de natureza bastante distinta: enquanto a teoria da história buscou nos textos históricos entender suas estruturas narrativas, esclarecer seus conceitos, avaliar seus argumentos e verificar como viradas temáticas ou conceituais se relacionavam a eventos exteriores ao texto, a análise que proponho na esteira de Paul visa mapear discursos de avaliação - discursos cuja finalidade não é necessariamente substantiva para a história, mas sim normativa. Assim, estudam-se textos não mais para perscrutar as regras que o estruturam enquanto narrativa histórica, mas as regras que estruturam as práticas que Ihe antecedem e Ihe deram forma, conteúdo e sentido.

\section{Persona acadêmica}

Os repertórios de virtudes epistêmicas de que dispõem os grupos produtores de conhecimento se articulam a outras dimensões, como comprometimentos e objetivos éticos, políticos e econômicos, no que Paul chama de persona acadêmica (PAUL 2011; 2014; 2016). Tratam-se de modelos de conduta, tipificações abstratas que servem de parâmetro em relação aos quais os indivíduos que pertencem ou desejam pertencer ao grupo se posicionam para serem reconhecidos como tal - exemplos hipotéticos seriam o historiador engajado da New Left, o historiador arquivista do século XIX europeu, ou mesmo o historiador cientista dos Annales. ${ }^{6}$

\footnotetext{
5 Assim, aproprio-me de Paul a partir de uma situação particular - aquela da perspectiva da arqueogenealogia avançada por Michel Foucault - apoiado também na concepção de genealogia problematizadora, na interpretação oferecida por Colin Koopman (2011). Neste sentido, compreendo a constituição e a configuração de virtudes epistêmicas como um aparato, um mecanismo de produção de subjetividade e de disciplinarização, a partir do qual produzem-se sujeitos autorizados a falar do passado de uma determinada maneira, em um determinado código - autorizados pelo lugar.

${ }^{6}$ Destes, apenas o segundo já conta com estudos publicados a seu respeito. Assim, aos outros, é preciso tomá-los pelo que são - hipóteses muito elementares. Sobre o historiador arquivista, ver os textos de Paul (2013), Pieter Huistra (2013) e Kasper Eskildsen (2013).
} 
Daston e Otto Sibum, em 2003, propuseram aos historiadores da ciência a categoria de persona científica, definindo-a como "uma identidade cultural que simultaneamente molda o indivíduo em corpo e mente, e cria um coletivo com uma fisionomia compartilhada e reconhecível" (DASTON; SIBUM 2003, p. 2). Investigar a emergência dessas categorias possibilitaria investigar a história da ciência enquanto uma história de intervenção subjetiva, no corpo e na mente dos indivíduos que se arrogariam o rótulo de "cientista". Assim, para eles, o conceito de persona se preocupa "[...] com a emergência e as implicações de categorias de pessoas - de maneiras coletivas de pensar, sentir, julgar, perceber, trabalhar - mais do que com biografias individuais em toda sua particularidade idiossincrática" (DASTON; SIBUM 2003, p. 3).

Em outro front, Conal Condren, Stephen Gaukroger e Ian Hunter propuseram que o conceito de persona seria uma ferramenta importante para a história da filosofia, mostrando que as distinções entre escolas e doutrinas filosóficas estava mais relacionada com diferentes maneiras de conceber o ser do filósofo do que com um debate racional de proposições. Para eles, a persona é "o 'si mesmo' ['self'] construído propositadamente, cujas capacidades cognitivas e capacidade moral são cultivadas em prol de um conhecimento tido por filosófico" (CONDREN et al. 2006, p. 7).7

De ambas as perspectivas, como também para Paul, mas de maneiras diferentes, o conceito de persona designa diferentes maneiras de ser algo cientista, para Daston e Sibum, filósofo, para Condren, Gaukroger e Hunter, ou historiador, para Paul. Evidentemente, cada uma das três abordagens traz suas próprias particularidades teóricas e suas dificuldades metodológicas. Dos primeiros, o alto nível de abstração faz com que a tipologia cubra vastas escansões de tempo; para os segundos, aquilo que nos acostumamos a ver como disputas entre escolas filosóficas implicam em disputas entre diferentes personas de filósofos, o que compreenderia períodos muito mais curtos de tempo. A proposta de Paul parece ficar entre ambas: as personas do historiador talvez não flutuem tanto quanto na filosofia, mas certamente são mais diversas do que as figuras que Daston e Sibum propõem estudar na história da ciência (PAUL 2014; 2016). Ademais, a tensão entre os modelos ideais de conduta e o exercício desses valores faz com que apenas através da leitura atenta de um conjunto expandido de casos individuais possamos entender como diferentes acadêmicos se posicionaram em relação às referências disponíveis em suas circunstâncias. Assim, "descontando casos excepcionais, os acadêmicos não viviam uma única persona, mas inspiravam-se nas personae disponíveis, no plural, para construírem-se a si mesmos [to fashion their own scholarly selves] no que possivelmente foi, com frequência, um balanço entre convenção e invenção" (PAUL 2016, p. 335).

Virtudes e personae enquanto objetos e campos de disputa: atentarse às formações discursivas que faziam funcionar determinados modelos de

\footnotetext{
7 Hunter, em texto solo, oferece a definição em outros termos: "A persona do filósofo é entendida como um tipo especial de si mesmo [self], cultivado por membros seletos da elite intelectual Europeia como os meios de portar conhecimento filosófico" (HUNTER, 2007, p. 574).
} 
historiografia, eis a ementa mais geral de um programa de pesquisa que, parece-me, não precisa se limitar à academia europeia dos séculos XVIII e XIX (OHARA 2016). Neste sentido, volto-me para uma série constituída por três textos de segunda ordem - duas resenhas e um artigo de avaliação e balanço historiográfico ${ }^{8}$ - para mapear um tema recorrente nesses materiais, qual seja, o da sensibilidade histórica. Que poderia constituir sensibilidade histórica no repertório de valores e condutas de que dispunham os historiadores brasileiros dos anos de 1980 a 1990 ? $^{9}$ Entre as resenhas e os ensaios bibliográficos publicados em periódicos acadêmicos de história no período delimitado, a referência à sensibilidade histórica aparece nos três exemplares aqui selecionados; tratandose de gêneros avaliativos, ou seja, nos quais os pesquisadores veiculam julgamentos a respeito do trabalho de seus pares, pareceu-me particularmente adequado investigar como o tema poderia emergir nessas discussões.

\section{Sensibilidade histórica como virtude}

No recorte proposto por este trabalho, a expressão sensibilidade histórica aparece pela primeira vez em texto de Francisco Iglésias, quando este se refere a Caio Prado Jr.: "Este [Caio Prado Jr.] já é um historiador dedicado principalmente à sua ciência: embora advogado de formação, é das sensibilidades históricas mais notáveis que o país já teve" (IGLÉSIAS 1983, p. 132). Mais adiante, o autor também celebra a grande sensibilidade de Marc Bloch (IGLÉSIAS 1983, p. 136), e censura a falta dela nas Histórias do Direito escritas por advogados (IGLÉSIAS 1983, p. 139). Em nenhum momento Iglésias faz questão de explicitar aquilo que entende pelo termo, mas uma leitura atenta da peça pode nos dar indícios interessantes. Primeiramente, o autor celebra entre os historiadores aqueles que dominam não apenas as técnicas da crítica documental, mas também as ferramentas de outras ciências sociais:

No caso da História, é certo que quem a cultiva com o domínio de algo mais que as técnicas específicas conseguem trabalhos de nível superior. Quem pesquisa e coleta milhares de documentos, mas não os organiza em certa linha interpretativa, pode fazer um catálogo, não fará obra significativa (IGLÉSIAS 1983, p. 134).

A capacidade de transitar entre as técnicas típicas da história e os insights de disciplinas avizinhadas seria crucial no desenvolvimento de uma "obra significativa". Apenas pelo recurso à interdisciplinaridade o historiador poderia

\footnotetext{
${ }^{8}$ A resenha enquanto gênero de avaliação recebeu alguma atenção no campo da crítica literária (cf. BONDI; SANZ 2014; HYLAND; DIANI 2009; MOTTA-ROTH 1998); na história, o estudo de resenhas é ainda tímido e pouco expressivo, ainda que se reconheça seu valor enquanto fonte. Fabio Franzini apresentou dois trabalhos sobre resenhas em duas edições do Seminário Nacional de História da Historiografia, mas nenhum dos textos parece ter sido publicado posteriormente. Sabrina Magalhães Rocha também apresentou trabalho sobre resenhas como fonte para a história da historiografia, mas igualmente não publicou o texto final. Ademais, a resenha aparece de maneira mais comum como fonte auxiliar em meio a outros tipos de documentos.

9 O tema mais geral da "sensibilidade histórica" não é, certamente, uma novidade da historiografia moderna. Thierry, em carta de 1820, já mencionava a importância da sensibilidade do historiador que viria a escrever a "verdadeira" história da França (THIERRY 1835, p. 326). Quando Certeau cita Michelet na abertura de A Escrita da História, também evoca imagens de sensibilidade (CERTEAU 2008, p. 13-14). Este artigo, no entanto, fica detido à análise do material selecionado, optando por deixar o trabalho de erudição para outra ocasião.
} 
encontrar subsídios para "dar forma" à sua narrativa, uma vez que as ligações entre os acontecimentos não se dão naturalmente ao pesquisador. Mas logo em seguida Iglésias alerta seus leitores:

No caso, como sempre - assim ensina o lugar comum - a verdade está no uso correto da interdisciplinaridade, não em seu abuso distorsivo [sic]. Se sem o apelo a alguma teoria que dê forma e consistência à interpretação o esforço do pesquisador pode dar em produtos finais bem pífios, no caso de seu apelo excessivo o resultado pode ser também pífio, embora às vezes brilhante e enganador nas aparências. É que o historiador se deixa dominar pela outra ciência, passando-a de auxílio a instrumento diretor do trabalho. E absorve e incorpora não só o indispensável para o bom proveito, mas até o modo de ver, a técnica de manipulação dos dados, chegando mesmo a conclusões que nada têm a ver com a História (IGLÉSIAS 1983, p. 134, grifo meu).

Otermo central aqui é "o modo de ver": o "uso correto da interdisciplinaridade" se daria quando o historiador, munido de ferramentas "emprestadas" de outras disciplinas, não se deixa levar pelas maneiras de proceder de outras áreas. Em outras palavras, quando ele não deixa de exercer seu "olhar de historiador". Assim, entre a "sensibilidade" e o "olhar", Iglésias deixa entrever que existe algo de específico, de particular e peculiar na maneira pela qual os historiadores apreendem o mundo, organizam suas referências e produzem seu conhecimento. Essa será a chave para entendermos melhor a que enunciado ele se refere quando trata da expressão sensibilidade histórica. Ora, diz Iglésias da tarefa central do historiador:

Situar no tempo, exprimir quanto se dá sob o signo de suas características, é a tarefa básica do historiador. Cabe-Ihe interessar-se por todas as temporalidades, não se apegando apenas ao passado, segundo conceito genérico e limitado. [...] A capacidade de captar a mudança é um dos traços distintivos do historiador (IGLÉSIAS 1983, p. 135).

Então, "situar no tempo" define, para o autor, a tarefa fundamental do historiador - sua especificidade entre as ciências sociais. ${ }^{10}$ Eis que, logo adiante, Iglésias ligará essa concepção de historiar com o elogio da sensibilidade histórica de Marc Bloch:

Quem melhor conceituou a especialidade foi Marc Bloch, em livro citado [Apologia da História], quando refuga a idéia de História ser só o passado e diz de seu interesse pelo presente, preferindo dizer que a História é o estudo do homem no tempo. Compreende pois o passado e o presente. [...] Pode fazê-lo [a apologia da história] exatamente por sua alta sensibilidade histórica, que o levava a compreender o instante e a não ter dúvidas quanto a sua breve mudança (IGLÉSIAS 1983, p. 136, grifo meu).

\footnotetext{
${ }_{10}$ Ver também, por exemplo, na crítica de Iglésias à periodização da historiografia brasileira por Silvio Romero: "Ora, 'fases de evolução' significam propósito de periodizar, mas, no modo feito, constituem apenas aproximação ou forma imprecisa de periodização, trabalho difícil e dispensável na historiografia, pois a categoria básica do conhecimento histórico é o tempo, a compreensão da história sendo a das diferentes temporalidades, nas quais se apura e se afirma o verdadeiro cultor do gênero" (IGLÉSIAS 2000, p. 21, grifo meu).
} 
Assim, não seria de todo absurdo esboçar uma primeira definição de sensibilidade histórica neste contexto, em ligação à "tarefa básica" do historiador: sensibilidade histórica é a capacidade de situar no tempo. A sensibilidade histórica seria, portanto, aquilo que permite ao historiador instrumentalizar a interdisciplinaridade sem perder de vista o tempo histórico. Munido dessa capacidade, o historiador pode lançar mão de conceitos, teorias e modelos de outras disciplinas (como o fizeram os "pais fundadores" dos Annales) de maneira a subordiná-los à perspectiva do tempo histórico, esta sim central ao conhecimento que se pretenda histórico. Ceder à interdisciplinaridade sem sensibilidade histórica significa abrir mão daquilo que é específico, particular e caro ao historiador; significaria fazer coisa outra que não história.

Neste primeiro sentido, podemos dizer que a sensibilidade histórica constitui por si só uma virtude epistêmica: é pelo seu exercício adequado que se pode agir virtuosamente enquanto historiador. Em outros termos, aquilo que diferencia a pesquisa histórica daquela das outras ciências sociais é a capacidade do historiador situar os elementos de sua história no tempo. Logo, trata-se de uma capacidade desejável do pesquisador que deseja ser historiador. É possível encontrar outros subsídios para corroborar essa leitura mais adiante no mesmo texto, quando o autor repreende a falta de sensibilidade histórica nos livros de História do Direito escritos por advogados:

Lembrem-se, por exemplo, os [livros] de História do Direito produzidos por advogados. Alguns até de grandes juristas, homens superiormente afirmados em suas áreas. Falta-Ihes porém a sensibilidade histórica e seus livros valem pouco ou até quase nada como História (IGLÉSIAS 1983, p. 139, grifo meu).

Eruditos, mas incapazes de situar os elementos de suas histórias em uma cadeia mais ampla de acontecimentos - situar suas histórias no tempo - esses livros de História do Direito teriam pouco a acrescentar à nossa compreensão histórica do Direito. Estariam mais próximos dos "catálogos" antes mencionados; coleções de fatos, colocados um após o outro, presumindo-se que post hoc ergo propter hoc. Iglésias completa mais adiante:

Demais, o historiador sem formação adequada [...] tem conhecimento reduzido do processo evolutivo. Interessa-se por certo tema ou época, por capricho ou afinidade com a área em que se especializou: faz o seu estudo, mas não tem informação sobre quadro amplo, de modo que comete erros elementares ou é incapaz de colocar o assunto em contexto geral; daí a produção padecer de insuficiência ou mesmo equívocos (IGLÉSIAS 1983, p. 139-140, grifo meu).

Aqui, parece-me interessante que o autor menciona a questão da formação. Considerando que nos anos de 1980 estamos começando a colher os frutos da expansão da pós-graduação iniciada na década anterior, a ligação entre a ideia de formação e o problema da sensibilidade histórica é importante: trata-se, afinal, de uma disposição cultivada, passível de ser ensinada e aprendida, e não de um dom divino. O exercício da sensibilidade histórica, ligado à ideia 
de formação adequada, aponta para a hipótese de que as características tidas por virtuosas no exercício do ofício do historiador são parte de um mecanismo mais amplo de produção de subjetividade. Produz-se o indivíduo capaz de falar do passado de maneira legítima, tanto quanto se produzem discursos sobre o passado. ${ }^{11}$ No caso específico, Iglésias se refere a determinada concepção de história para a qual os temas de "quadro amplo" e "contexto geral" seriam centrais; trata-se de uma formação capaz de cultivar nos alunos a sensibilidade histórica tal qual definida anteriormente.

\section{Sensibilidade histórica como meta-virtude}

Nas outras duas peças nas quais a sensibilidade é evocada, no entanto, essa definição fica menos clara. Laura de Mello e Souza, por exemplo, elogia a sensibilidade com que Ronaldo Vainfas opera a análise dos discursos jesuíticos sobre a escravidão africana: "Feita com sensibilidade e erudição, a análise dos enunciados destes discursos é o ponto alto do livro. Neles, o Autor detecta a presença da patrística, da escolástica, da filosofia grega [...]" (SOUZA 1987, p. 202). Aqui, a sensibilidade e a erudição se mesclam; seria a sensibilidade a capacidade de decompor o discurso jesuítico com relação às referências intelectuais ali presentes? Tal entendimento estaria, de certa maneira, alinhado à concepção evocada por Iglésias, no sentido de localizar discursos em relação a uma cadeia maior de elementos. Por outro lado, pode-se começar a pensar a sensibilidade como algo diferente. Poderíamos pensar aqui em uma expressão que aglutina várias habilidades e disposições outras, dando a elas um sentido específico - o do ofício de historiar. Nesse caso particular, o exercício da sensibilidade histórica de Vainfas parece estar ligado à combinação de sua erudição com a atenção aos detalhes e o rigor de análise, no sentido de que a erudição torna significativo o detalhe enquanto evidência histórica. Vê-se, portanto, que a própria definição de sensibilidade histórica está intimamente ligada à concepção de história dos autores - e, consequentemente, a outros enunciados e configurações de virtudes epistêmicas.

Outro caso será útil para tentar esboçar um melhor entendimento do que poderia ser essa sensibilidade enquanto meta-virtude, ou uma virtude que dá sentido a outras. Ao resenhar Linhagens do Estado Absolutista, de Perry Anderson, Modesto Florenzano também dá margem a percebermos essa distinção. Assim ele comenta:

Perry Anderson não é um historiador profissional, seus estudos não são o resultado de um trabalho de pesquisa, em primeira mão, nos documentos históricos, mas são o fruto de uma "simples leitura de trabalhos publicados por historiadores contemporâneos, o que é uma outra coisa". Não nos deixemos impressionar, contudo, por esta confissão dos limites da obra.

\footnotetext{
${ }_{11}$ Lembre-se que Iglésias via com certo entusiasmo a profissionalização da historiografia em sua forma universitária - em especial conforme expresso na obra, publicada postumamente,Historiadores do Brasil, na qual, apesar de tal entusiasmo, pondera que essa nova modalidade de formação "é recente e nunca faltou historiografia, às vezes do melhor nível. Algumas de suas obras primas são mesmo antigas, fruto do talento ou do gênio, da criação ou da garra de autores de sensibilidade para a mudança, para a história" (IGLÉSIAS 2000 , p. 230-231, grifos meus).
} 
Todos os seus trabalhos têm revelado um talento e sensibilidade raros que só os grandes, os autênticos historiadores possuem (FLORENZANO 1984, p. 75-76).

Fica pouco claro, novamente, o que Florenzano entende por "sensibilidade", uma qualidade que apenas os "grandes" e "autênticos" historiadores possuiriam. Mas é significativo que o resenhista marque que, apesar de não ser "historiador profissional", e de seus estudos não serem fruto de "trabalho de pesquisa, em primeira mão, nos documentos históricos", apesar de tudo isso o autor resenhado seria possuidor de uma qualidade subjetiva que o tornaria um historiador de primeira grandeza.

Mais adiante em sua resenha, o autor celebra a capacidade de Anderson trabalhar com colegas das mais diversas matrizes teóricas:

Daí a riqueza de análise e interpretação que o autor nos oferece, isto é, do uso absolutamente inteligente e criativo dos trabalhos dos historiadores de todos os matizes teóricos. Daí também a fecundidade das suas reflexões, da sua teorização, isto é, da utilização, ao mesmo tempo, plena e rigorosa, mas não sacralizada, do materialismo histórico (FLORENZANO 1984, p. 76).

Aqui, mais do que uma habilidade ou disposição específica, a sensibilidade aparece como um campo no qual se organizam outras virtudes epistêmicas: open-mindedness, no caso, mas também a capacidade de síntese, a honestidade intelectual e a erudição. Essa hipótese de leitura abre, portanto, uma divergência em relação à concepção avançada em Iglésias. Os autores parecem lidar com duas concepções de sensibilidade histórica distintas: de um lado, uma capacidade específica, passível de ser treinada, aprendida e ensinada; de outro, um termo que aglutina outras habilidades e disposições, e que dá um sentido ao trabalho do historiador. A primeira dessas concepções atua como virtude, ou seja, como capacidade cujo exercício é desejável para o exercício da atividade historiadora; a segunda atua como meta-virtude, ou seja, como atributo direcionador que organiza o exercício das capacidades desejáveis do historiador.

\section{Considerações finais}

Mais do que procurar desfazer essas ambiguidades, aquilo que me interessa mais nestes casos é explorar justamente os diferentes enunciados aos quais os resenhistas se referem usando uma mesma expressão. Isso porque os historiadores operam com repertórios limitados de características desejáveis. É neste sentido que apenas a leitura atenta dos textos nos quais essa linguagem axiológica é instrumentalizada pode fornecer subsídios para a pesquisa. Não se trata tanto de revelar algum sentido oculto por trás das palavras, mas de descrever as relações discursivas estabelecidas na superfície dos textos. ${ }^{12}$ No caso da sensibilidade histórica, foi possível descrever duas formações

12 Retomando aqui a figura elaborada por Foucault segundo a qual o enunciado não é visível, mas não é oculto. Ver Foucault (2012). 
discursivas específicas em relação às quais os historiadores se situavam. De um lado, acompanhando uma concepção processual da história, a sensibilidade histórica designa a capacidade do historiador situar elementos individuais em cadeias maiores, dando-Ihes um sentido e estabelecendo as relações entre esses elementos. De outro, a sensibilidade histórica designa o sentido do próprio fazer historiográfico, aglutinando outras habilidades desejáveis por parte do historiador - erudição, atenção aos detalhes, rigor de análise, open-mindedness, capacidade de síntese, etc. Tratam-se de duas formações que exercem funções diferentes na produção de subjetividade do historiador. Enquanto uma designa uma habilidade que pode ser aprendida, a outra dá um sentido que organiza certas competências do indivíduo.

Ademais, a análise das formações discursivas levada a cabo neste texto se detém em uma descrição sincrônica do fenômeno. Neste sentido, o que aqui se esboçou é uma espécie de retrato, ainda que inicial, da configuração do enunciado "sensibilidade histórica" na historiografia acadêmica brasileira entre 1980 e 1990. Trata-se, enfim, de um primeiro passo que, parece-me, pode seguir para leituras diacrônicas, comparativas, mas tal esforço fica além dos objetivos deste texto, de caráter mais modesto.

Para além do caso específico da sensibilidade histórica, parece-me plausível que a hipótese avançada por Paul, de que os historiadores (1) lidam com repertórios limitados de valores e condutas exemplares e (2) se situam em tensão entre os pontos de referência disponíveis nesses repertórios, não se esgota nos séculos XVIII e XIX, tampouco ao recorte geográfico da Europa. Avanço a reflexão, portanto, apontando que a linguagem, ou, mais ainda, a concepção "moralizante" do ofício do historiador não é traço arcaizante, reminiscência de um Antigo Regime historiográfico, mas é constitutiva de uma maquinaria que produz sujeitos aptos a serem historiadores. ${ }^{13}$ Moralizante no sentido de que fundamenta o sucesso da empreitada histórica no sujeito produtor e em suas características subjetivas - a posse, o cultivo e o exercício de virtudes epistêmicas. Essa maquinaria, que entendo fazer parte daquilo que Certeau chamou de lugar social, permanece indissociável da capacidade de produção de sentido por parte da história. Faríamos bem em nos atentarmos para as consequências dessa questão.

\section{Referências bibliográficas}

BONDI, Marina; SANZ, Rosa Lorés (Ed.). Abstracts in Academic discourse: variations and change. Bern: Peter Lang, 2014.

CERTEAU, Michel de. A Escrita da História. 2. ed. Rio de Janeiro: Forense Universitária, 2008.

\footnotetext{
13 Para momentos ainda mais recentes, poderíamos chamar a atenção para as discussões em torno de como o historiador deveria se colocar em disputas políticas - como no caso do debate em torno do impeachment/ golpe de Dilma Rousseff, ou da proposta "Escola sem partido" - que mobilizam discussões antigas em torno das relações entre comprometimento político e escrita da história, dos temas da objetividade; em suma, em torno de "modos de ser" historiador, ligados a concepções distintas de história.
} 
- História e Psicanálise: entre ciência e ficção. Belo Horizonte: Autêntica, 2011.

CONDREN, Conal; GAUKROGER, Stephen; HUNTER, Ian (Eds.). The Philosopher

in Early Modern Europe: the nature of a contested identity. Cambridge (UK): Cambridge University Press, 2006.

DASTON, Lorraine; GALISON, Peter. Objectivity. New York: Zone Books, 2007. ; LUNBECK, Elizabeth (Eds.). Histories of Scientific Observation. Chicago: The University of Chigaco Press, 2011.

; SIBUM, H. Otto. Introduction: Scientific Personae and Their Histories.

Science in Context, v. 16, n. 1-2, p. 1-8, 2003.

DELACROIX, Christian; DOSSE, François; GARCIA, Patrick; TREBITSCH, Michel (Dir.). Michel de Certeau: les chemins d'histoire. Bruxelles: Éditions Complexe, 2002.

ESKILDSEN, Kasper Risbjerg. Inventing the archive: testimony and virtue in modern historiography. History of the Human Sciences, v. 26, n. 4, p. 8-26, 2013.

FLORENZANO, Modesto. Resenha de Perry Anderson, Linhagens do Estado Absolutista, Porto 1984 (tradução do original: LineagesoftheAbsolutistState, New Left Books, Londres, 1976). Projeto História, São Paulo, n. 3, p. 75-77, 1984.

FOUCAULT, Michel. A Arqueologia do Saber. 8. ed. Rio de Janeiro: Forense Universitária, 2012.

FROEYMAN, Anton. Virtues of Historiography. Journal of the Philosophy of History, v. 6, n. 3, p. 415-431, 2012.

GIARD, Luce; MARTIN, Hervé; REVEL, Jacques. Histoire, Mystique et Politique: Michel de Certeau. Grenoble: JérômeMillon, 1991.

GRECO, John. Virtue Epistemology. In: DANCY, Jonathan; SOSA, Ernest; STEUP, Matthias (Eds.). A Companion to Epistemology. 2. ed. Chichester: Wiley-Blackwell, 2010, p. 75-82.

HUISTRA, Pieter. The trial of Henry of Brederode: historians, sources and location under discussion in 19th-century historiography. History of the Human Sciences, v. 26, n. 4, p. 50-66, 2013.

HUNTER, Ian. The History of Philosophy and the Persona of the Philosopher. Modern Intellectual History, v. 4, n. 3, p. 571-600, 2007.

HYLAND, Ken; DIANI, Giuliana (Eds.). Academic Evaluation: review genres in university settings. Basingstoke: Palgrave Macmillan, 2009.

IGLÉSIAS, Francisco. A Historiografia Brasileira Atual e a Interdisciplinaridade. Revista Brasileira de História, v. 3, n. 5, p. 129-141, 1983.

Historiadores do Brasil. Belo Horizonte: Ed. UFMG, 2000. 
KVANVIG, Jonathan. Virtue Epistemology. In: BERNECKER, Sven; PRITCHARD, Duncan (Ed.). The Routledge Companion to Epistemology. London: Routledge, 2011, p. 199-207.

MOTTA-ROTH, Désirée. Discourse Analysis and Academic Book Reviews: a study of text and disciplinary cultures. In: COLL, J. F.; FORTANET, I.; PALMER, J. C.; POSTEGUILLO, S. (Ed.). Genre Studies in English for Academic Purposes. Castellón: UniversitatJaume I, 1998, p. 29-48.

OHARA, João Rodolfo Munhoz. The Disciplined Historian: "epistemic virtue", "scholarly persona", and the practices of subjectivation. A proposal for the study of Brazilian professional historiography. Práticas da História, v. 1, n. 2, p. 39-56, 2016.

PAUL, Herman. Performing History: how historical scholarship is shaped by epistemic virtues. History \& Theory, v. 50, n. 1, p. 1-19, 2011.

. The heroic study of records: The contested persona of the archival historian. History of the Human Sciences, v. 26, n. 4, p. 67-83, 2013.

. The Virtues and Vices of Albert Naudé: toward a history of scholarly personae. History of Humanities, v. 1, n. 2, p. 327-338, 2016.

. Virtue Ethics and/or Virtue Epistemology: a response to Anton Froeyman. Journal of the Philosophy of History, v. 6, n. 3, p. 432-446, 2012a.

. Weak Historicism: On Hierarchies of Intellectual Virtues and Goods. Journal of the Philosophy of History, v. 6, n. 3, p. 369-388, 2012b.

. What is a Scholarly Persona? Ten theses on virtues, skills, and desires.

History \& Theory, v. 53, n. 3, p. 348-371, 2014.

SOSA, Ernest. The Raft and the Pyramid: coherence versus foundations in the theory of knowledge. Midwest Studies in Philosophy, [s.i.], v. 5, n. 1, p. 3-25, 1980.

SOUZA, Laura de Mello; VAINFAS, Ronaldo. Ideologia e Escravidão - os letrados e a sociedade escravista no Brasil Colonial. Petrópolis, Vozes, 1986, 168

p. Revista Brasileira de História, v. 7, n. 13, p. 199-204, 1987.

THIERRY, Augustin. Dix Ans d'Études Historiques. Paris: Just Tessier, 1835.

ZAGZEBSKI, Linda. Virtues of the Mind. Cambridge: Cambridge University Press, 1996. 